\title{
INTENSITY OF INUOLVEMENT OF TEACHERS AND RESEARCHERS FROM ROMANIAN UNIVERSITIES IN BIOECONOMY KNOWLEDGE FLOWS
}

\author{
Andrei Ștefan Neștian ${ }^{1}$, Silviu Tiță ${ }^{2}$ and Alexandra Luciana Guță ${ }^{3 *}$ \\ 1), 2), 3) Alexandru Ioan Cuza University, Iași, Romania
}

\section{Please cite this article as:}

Neștian, A.Ș., Tiță, S. and Guță, A.L., 2018. Intensity of Involvement of Teachers and Researchers from Romanian Universities in Bioeconomy Knowledge Flows. Amfiteatru Economic, 20(49), pp. 567-582

\section{Article History}

Received: 30 March 2018

Revised: 20 May 2018

Accepted: 21 June 2018

\section{DOI: $10.24818 / \mathrm{EA} / 2018 / 49 / 567$}

\begin{abstract}
This article is the result of a study aimed to identify the intensity of knowledge flows related to bioeconomy, between Romanian universities and other organizations. Using answers to a questionnaire addressed to faculty and researchers working in research areas linked to bioeconomy, and the principal component analysis, we have identified a set of five components explaining variations in intensity of their involvement in knowledge flows related to bioeconomy development by engaging in specific sets of activities. The headings Bio-Academic, Bio-Tech\&Science, Bio-Entrepreneurship, Bio-Ambassador and Bio-Expert were attributed to the five components. The average level of involvement in bioeconomy of the respondents in the sample is almost minimal, which confirms the opinions from the analysed literature. The highest level of involvement was found in activities under the BioAcademic and Bio-Tech\&Science components. The lowest intensity of involvement is linked to Bio-entrepreneurship.
\end{abstract}

Key-words: knowledge flows, bioeconomy, knowledge economy, intellectual capital, universities, bio-entrepreneurship, biotechnology

JEL classification: D83, I23, I25, O13

\section{Introduction}

Found at the crossroads of several scientific fields, knowledge management proposes a set of concepts, perspectives and applications which, starting from the individual and the organization, may be applied to the size of big socioeconomic systems. Study of knowledge flows in organizations is a type of analysis that belongs to a sub-field of management. In the context of current development of bioeconomy as a specific socioeconomic system,

* Corresponding author, Alexandra Luciana Guță - luciana_guta@yahoo.com 
knowledge flows among its economic actors have been recognized as key factors for development (European Commission (EC), 2012). The role of universities in economic development processes is based on their contribution to the growth of intellectual capital, through knowledge flows that universities develop with other organizations. Economic development has currently led to a distinction among different types of economy, bioeconomy being one of the most debated. In bioeconomy, universities are seen as firstorder actors due to the role they play in the increase of the regional intellectual capital.

In this research, we started from a set of observations from the literature in the field and the institutional reports that underline the existence of implied links between the intensity of knowledge flows between member organizations of the economic ecosystem and the level of development of bioeconomy (Clever Consult, 2010; EC, 2012; Spatial Foresight, 2017). Out of actors involved in bioeconomy development, we selected universities due to their generating role, adequate to be studied in any state of development of bioeconomy, from its emergence to maturity. This study focuses on involvement of Romanian universities in knowledge flows related to bioeconomy development, through their faculty and researchers.

\section{Bioeconomy}

„The bio-economy is one of the oldest economic sectors known to humanity, and the life sciences and biotechnology are transforming it into one of the newest" (European Comission (EC), 2005, p. 2). This coming back of mature economic sectors with low chances of economic growth is due to outstanding development of science and technology. „Bio-based economy (bioeconomy) is a promising sector with notable future potential and many business opportunities" (Luoma, Vanhanen and Tommila, 2011, p. 20). This new potential is due to adoption of a new vision on these sectors, as shown in current definition of bioeconomy. This vision rests on the idea of the bioeconomy as ,the aggregate set of economic operations in a society that use the latent value incumbent in biological products and processes" (Organisation for Economic Co-operation and Development (OECD), 2006, p. 3). Moreover, high attention has been given due to the link between bioeconomy and sustainability of global economy. „The bioeconomy cross-cutting nature offers a unique opportunity to comprehensively address inter-connected societal challenges such as food security, natural resource scarcity, fossil resource dependence and climate change, while achieving sustainable economic growth" (EC, 2012).

Bioeconomy „can be defined as the exploitation and management of renewable natural resources in a sustainable way. It includes producing different products and services by using various biological and technical applications" (Kuisma, 2010 cited in Näyhä, 2012, p. 13). Henry and Trigo $(2010$, p. 2) state that bioeconomy ,is defined as the utilization of biology - and biological processes - in economic activities." A specific feature of bioeconomy is its localisation at the intersection of several industries. „According to the European Commission (2011), the concept of bioeconomy brings under one umbrella all sectors - agriculture, forestry, fisheries, food, biotechnology and the chemical industry- of the economy that process biological resources from different ecosystems. It relies on research from bio-sciences, information technologies, robotics and materials and aims to transform the knowledge and new technologies into agricultural, industrial and social innovation” (Näyhä, 2012, p. 13). „The Bioeconomy refers to the sustainable production 
and conversion of biomass into a range of food, health, fibre, industrial products and energy." (Saviotti, 2017, p. 17). The bioeconomy „encompasses the production of renewable biological resources and the conversion of these resources and waste streams into value added products, such as food, feed, bio-based products and bioenergy" (EC, 2012 , p. 9). This broad vision on bioeconomy is reflected in its economic sectors and in the types of included products. „The bioeconomy includes the sectors of agriculture, forestry, fisheries, food and pulp and paper production, as well as parts of chemical, biotechnological and energy industries” (EC, 2012, p. 3). „In a bioeconomy, resources come from plants, animals, or micro-organisms. In production, it also uses biological processes for a more sustainable production that conserves energy and resources" (Dabbert, et al., 2017, p. V). According to the European Commission, in the bioeconomy, primary production includes "agriculture, forestry, fisheries and aquaculture" (EC, 2012, p. 9). Biobased products are products that are wholly or partly derived from materials of biological origin, excluding materials embedded in geological formations and/or fossilised" (EC, 2012, p. 9).

Scientifically, bioeconomy uses general knowledge from several scientific fields. „The bioeconomy relies on life sciences, agronomy, ecology, food science and social sciences, biotechnology, nanotechnology, information and communication technologies (ICT), and engineering" (EC, 2012, p. 9). This diversity of scientific areas that could contribute to bioeconomy development was taken into account in establishing the target population of respondents for this research. Diversity of required scientific knowledge is given by technological needs. Therefore, Oliver (2001, p. 471) mentions that „The European Federation of Biotechnology offers the following definition: biotechnology is the integrated use of biochemistry, microbiology and chemical engineering in order to achieve the technological (industrial) applications of the capacities of microbes and cultured tissue cells and parts thereof." According to OECD (2009) biotechnology is usually classified in three main headings as health biotechnology, industrial biotechnology, and primary production and agri-food biotechnology.

The intensity of the relation between bioeconomy development and use of new scientific knowledge and technology led to the notion of Knowledge-Based Bioeconomy (KBBE). The KBBE is based on "life sciences and biotechnology knowledge converging with other technologies to transform into new, sustainable, eco-efficient and competitive products" (Cologne Paper, 2007 cited in Clever Consult, 2010, p. 13). In a definition focused more on sustainability, Urmetzer and Pyka (2014) define knowledge-based bioeconomy as ,the production and dissemination of new knowledge about renewable biological resources and their potential to be sustainably converted into food, feed, bio-based products and bioenergy with the aim to overcome the wastefulness of production and consumption in its full dependency on fossil resources" (Urmetzer and Pyka, 2014, p. 2).

\section{Universities and knowledge flows related to Bioeconomy}

The biotechnology industry is considered to be ,especially important, since this knowledgeintense environment has been considered an illustrative industry in which organizational learning is located in the inter-organizational network" (Oliver, 2001, p. 482). Bioeconomy development is characterised by intensity of knowledge flows among socioeconomic actors. These flows become networks where contacts, information exchange, joint projects, 
personnel movement play the role of knowledge dissemination among actors. For example, universities have been traditionally educational and new knowledge creation centres, although this traditional view has been abandoned in the last decade becoming key players in the entrepreneurship or innovation ecosystem (Sengupta and Ray, 2017). "Knowledge sharing used in different ways constitute the best method for increasing the operational intellectual capital as a result of the increase of the average level of knowledge in university. Universities throughout the world search for opportunities to create networks based on shared values and academic interests." (Bratianu and Bejinaru, 2017). Old models of transfer from researcher to user are no longer used in new knowledge-based economy as these are placed in interactive models of network type that integrate knowledge production, its adaptation, use and education (Hocevar and Istenic, 2014). This model could be found in individual behaviour of faculty and researchers that now have complex portfolios of educational, research and science dissemination activities, as well as consultancy or direct involvement in business.

Knowledge flows are the key element that has been given a special role in the development of ecosystems for bioeconomy. Knowledge flows can be seen as a metaphor that is useful for analysing the knowledge transfer that takes place between two different economic players (Bolisani and Oltramani, 2012). Bratianu (2011, p. 64) mentions that „knowledge flows only due to a pressure difference between the emitter and the receiver." The knowledge flow should be oriented from an individual with a higher level of knowledge and understanding towards an individual with a lower level of knowledge and understanding (Bratianu and Orzea, 2013a, p. 136)

This is how Nissen (2006, p. XX) defines the concept of „knowledge flows”: „To the extent that organizational knowledge does not exist in the form needed for application or at the place and time required to enable work performance, then it must flow from how it exists and where it is located to how and where it is needed."

The knowledge flows are necessary for individual learning and for organizational learning to. Bratianu (2011, p. 64) considers that „knowledge flows from individuals to groups of people and then to the whole organization" and that, since organizations are open systems, „knowledge flows across boundaries toward the external business environment".

There are different forms of knowledge flows: knowledge transferred through consulting services or trainings, knowledge incorporated in services or products that are delivered and knowledge transferred through the exchange of services and products, before, during and after the exchange has taken place (Bolisani and Oltramani, 2012).

„The diversity of bioeconomy stakeholders in a given region and the need to bring them together and generate formal and informal spaces for knowledge exchange and transfer, for knowledge management and for preparing and taking joint decisions on strategic priorities, funding and implementation can be observed in most regions" (Spatial Foresight, 2017, p. 72). „Existing literature suggests that the clusters offer key competitive advantages with respect to three key variables: employment, innovation, and productivity." (PricewaterhouseCoopers, 2011, p. 2).

Involvement of universities in knowledge flows of Bioeconomy may be carried out, on the one hand, through licenses, patents, academic journals, research incubators funded by universities, joint research with other universities, and on the other hand, by involving personnel in providing consultancy for research departments of companies. The benefits 
brought by knowledge sharing are not just of economic nature, and found only in companies actively engaged in this process, but could be capitalized by the entire society by exploiting opportunities that appear after the implementation of research projects (An, Han and Park, 2017). A model for understanding the role of universities in generating and developing knowledge for any area of practice could be found in universities that have implemented programs of Knowledge Transfer Partnership (KTP) (Tuunainen and Kantasalmi, 2013). These are partnerships among, at least, one company, one university, students and graduates that are based on the identification of needs and problem-solving by transfer of experience, practices and results. Unfortunately, in many universities the organizational culture is based on the idea that performing research is compulsory for everybody (Bratianu and Bejinaru, 2017).

From a business perspective, the ability of faculty to take part in such collaborations is also an important factor. Specifically, the cultural differences between academic environment and business practices produce tensions among actors (Arvanitis, Kubli and Woerter, 2008; Ylijoki, 2003 cited in Clauss and Kesting, 2017). These often have different interests. Researchers wish to use these collaborations to achieve results that are specific to the research activities that they are engaged in, while businesses want to protect themselves in order to have exclusivity over the research outcomes as they believe that these cannot be protected by intellectual property rights.

Beyond previously mentioned roles, universities play a significant role in knowledge flows conveyed by their educational activities. This role is visible also in Bioeconomy „The new and interdisciplinary character of bioeconomy research and innovation requires also new approaches to education, training and capacity development. Some regions develop new, highly specialised or integrated/multidisciplinary education offers to satisfy skill needs of the bioeconomy" (Spatial Foresight, 2017, p. 73). Universities are main producers of experts that later engage in new types of emerging activities of Bioeconomy. In a study presenting the 6 determining endogenous factors of bioeconomy development, one of them is recognized as being „Specialised higher education, research and innovation activities within the region that stimulate research and innovation for the bioeconomy" (Spatial Foresight, 2017, p. 50). An action within the Bioeconomy Action Plan of the European Commission refers to building ,the human capacity required to support the growth and further integration of bioeconomy sectors by organising university fora for the development of new bioeconomy curricula and vocational training schemes." (EC, 2012, p. 14).

Several observations in the literature in the field report shortcomings linked to intensity of knowledge flows among actors involved in Bioeconomy. Some of them refer to relations of universities as centers of accumulation, production and dissemination of scientific and technological knowledge. „In order to better align academic knowledge to industry needs, industry will need to develop an earlier understanding of the application potential of new technologies provided by academia. Similarly, academic researchers will need a sharper focus on industry's needs and specifications. In addition, better interdisciplinary and collaborative research would also lead to new business activities" (Clever Consult, 2010, p. 60).

Problems in knowledge flows related to bioeconomy have also been discussed in terms of possible solutions to assessing the level of bioeconomy development. „A bioeconomy R\&I maturity index has been calculated for European regions and countries. It refers to a composite index taking into account the overall innovation capacity of a territory, the existence of specific bioeconomy features such as strategies or cluster, and the perceived 
intensity of bioeconomy R\&I activity" (Spatial Foresight, 2017, p. 9). In what regards maturity of Bioeconomy, Romania's Euro-regions are found only at levels 1, 2 and 3 on a 10-point scale, where 10 is the highest level of maturity. So, Romania's Euro-regions belong to least mature Euro-regions that are found at 0-3 levels, together accounting for $25,8 \%$ of total regions. „Regions or countries with a low bioeconomy maturity level tend to focus on value chain approaches <<biomass supply and waste〉> and <<biomass conversion and processing >>" (Spatial Foresight, 2017, p. 49). Therefore, we expect for the involvement intensity of Romanian universities in activities linked to bioeconomy to be low, under the average value of scales used in the suggested methodology, although some knowledge transfer activities could reflect a relative growth.

Sandu (2014) showed that knowledge transfer from research to business in Romania has been characterized in this way: research outcomes such as publications, patents, technical documentation have not been correlated with the research demands of businesses, and the intensity is of "in-house", with a low interest of private sector dominated by foreign companies, lack of initiatives aimed to grow the demand for research outcomes. There is a need for communication between universities and business communities in order to adapt programs to demands and needs of beneficiaries, and teachers should make efforts to develop the entrepreneurial spirit of students and to develop technological transfer networks (Popescu and Crenicean, 2012).

Another issue linked to knowledge flows is that of weak ties between universities and businesses. „Research and the application of its results are often disconnected due to an information and knowledge gap and institutional and conceptual barrier between researchers, innovators, producers, end-users, policy-makers and the civil society" (EC, 2012, p. 12). „Sometimes, a well-developed business sector leads regional innovation activities within the bioeconomy and looks for technological improvements and added value through innovation [...] In other cases, existing research and development activities at universities and innovation centres stimulate the interest in the bioeconomy" (Spatial Foresight, 2017, pp. 51-52). These weak ties also have an impact on educational processes, solutions being easy to identify but hard to implement. „By investing in education, students from various disciplines may acquire basic knowledge in bioeconomy in order to improve the ability of business and industry to switch to sustainable production in a number of areas" (Case Study Report Skåne cited in Spatial Foresight, 2017, p. 78).

Besides knowledge flows, another notion that we are referring to is the intensity of involvement in knowledge flows. We have taken two elements into account in order to define and measure the flow intensity: intensity of respondent's involvement in the types of activities mentioned in the questionnaire and the frequency of responses in the entire sample.

\section{Methodology}

\subsection{Hypotheses}

The research methodology was designed to discover the intensity of knowledge flows between Romanian universities and other organizations involved in bioeconomy development. 
We have formulated the following research hypotheses, grounded on literature review and by identifying technical solutions for validation:

- H1: Intensity of knowledge exchange (of respondents) differs by nature of conducted activities.

- H1.1: Knowledge exchange (of respondents) is more intense in academic than in other activities.

- H1.2: Knowledge exchange (of respondents) is least intense in entrepreneurial (compared with other activities).

- H2. Intensity of knowledge exchange (of respondents) is higher than the „lowest level of involvement (accidental, novel for the respondent)".

- H2.1. Intensity of knowledge exchange (of respondents) is higher than the ,lowest level of involvement (accidental, novel for the respondent)" for each component obtained using principal component analysis.

Based on the opinions of Nissen (2006, p. XX) and Bratianu (2011, p. 64), we considered that a knowledge flow is identifiable by the unidirectional transfer of knowledge between two actors. In the questionaire we are using both knowledge transfers from the respondents to other actors and from other actors to the respondents. Hence, in the hypothesys we use the concept of knowledge exchange, to ensure the consistency of all processing regarding all kind of interactions of the respondents, no matter the direction of the knowledge transfers.

\subsection{Target audience and sample}

The research was carried out by involving faculty and researchers from Romanian universities, and by selecting faculties that have links with the field of bioeconomy in 15 Romanian universities. Therefore, we identified 15 universities from all regions of the country, specialized in: (1) technology (Polytechnic University of Bucharest, Technical University of Cluj-Napoca, Gh. Asachi Technical University of Iași, Polytechnic University of Timișoara), from which were selected faculties of Chemical Enginring, Textiles and Leather, Materials Science and Economic faculties; (2) agriculture and veterinary medicine (University of Agricultural Science and Veterinary Medicine of Iași, Bucharest, ClujNapoca and Timișoara), being collected email of faculty and researchers in agriculture, horticulture, agricultural management, veterinary medicine, etc; (3) medicine (Universities of Medicine and Pharmacy of Cluj and Iași): faculties of medicine, pharmacy, biotechnologies; (4) science (Alexandru Ioan Cuza University of Iași, Babeș-Bolyai University of Cluj Napoca, West University of Timişoara and University of Bucharest), from which were selected faculties of chemistry, biology, geography and geology, economics and physics); (5) economics (the Academy of Economic Sciences of Bucharest).

From the mentioned universities, we collected and selected 2530 email addresses of faculty and researchers, to which two emails were sent. After the first email, 68 email invalid email addresses were recorded (addresses that did not receive the email due to various reasons). After the second email, there were 67 such addresses. So, the email reached 2462 valid email addresses during the first phase, and 2463 valid email addresses in the second phase. We received 354 responses, of which, 336 could be validated. 18 responses were eliminated as: 
(1) 14 of interviewed respondents reported that they were involved in activities related to bioeconomy but failed to complete the items of the questionnaire; (2) 1 person did not check on the questionnaire whether he or she was involved or not in the field; (3) 2 people did not complete any item; (4) 1 respondent completed just the academic title, without completing any item. The percentage of valid responses was 13,64\%. Out of 336 valid responses, 171 respondents responded to questionnaire items (whether all items, or some of them) - these were more or less involved in bioeconomy - which accounted for $6,94 \%$ of total number of responses. $6,70 \%$ of responses were "I have not been involved in the field of bioeconomy".

\subsection{Questionnaire}

The questionnaire was built in such a way that it made reference to knowledge flows in which are involved the members of academic community, including both the flows directed towards them and sent from them to other actors in bioeconomy. For measurement purposes, based on the opinion of Nissen (2006, p. XX), the flows were defined as activities that explicitly produce knowledge transfer from one actor of bioeconomy to another: from professor to students, from consultant to beneficiary, from researcher to companies by means of patents, etc. Depending on the main nature of activities in which faculty or researchers may be involved, three categories of knowledge flows were distinguished. First category is the flow of knowledge linked to direct relations of respondents and companies operating in bioeconomy. The second category is the flow of knowledge from educational activities in printed form that includes the involvement of faculty, students and interested employees. The third category is the knowledge flow from research activities that includes access to primary and secondary data in bioeconomy, production and dissemination to bioeconomy of knowledge from research. For all three types of flows, the items also referred to dissemination of knowledge to respondent and receiving it from.

Building on definitions of knowledge flows previously presented in the paper, part of the items in the questionnaire refer to knowledge flows derived from consulting or trainings; some items refer to knowledge flows related to products/ services that are delivered and some to flows from exchanges of either services or products. Thus, different forms of knowledge flows that are mentioned by Bolisano and Oltramari (2012) are covered through the questionnaire, with the mention that we focused on the intensity of involvement in knowledge flows (with a tendency of focusing on the first two forms of knowledge flows).

To measure flow intensity, two measurement elements were taken into account: relative intensity of respondent's involvement in the types of activities mentioned in questionnaire items, and frequency of responses in the entire sample. The scale used for the 35 used items for measuring the involvement ranged between: 0 (zero) - „I have never been involved” and 5 (five) - „Highest involvement (is is among your main concerns”, 1 (one) meaning „Lowest involvement (occasional, as a novelty for you)”, and 3 (three) meaning „Medium involvement".

\subsection{Methods and techniques used for data analysis}

To process and analyse data, we used Microsoft Excel - 2007 version and Statistical Package for the Social Sciences (SPSS) - version 20. The following types of analysis were conducted: reliability analysis, factor analysis (principal component analysis) and descriptive statistics. Reliability analysis was used to determine internal consistency of the 
instrument, the scale used for involvement in bioeconomy, and the results of extracted components. To extract the components (factors) of a construct, we used factor analysis of principal components. According to Hair, et al. (2006), it may be exploratory or confirmatory. We applied exploratory factor analysis as we could not identify similar studies, and the scale used to asess the involvement in bioeconomy had been proposed by the authors of the study. Descriptive statistics was used to interpret the results. For all analyses, the missing values were treated passively.

Regarding the use of exploratory factor analysis, we found similar approaches in the knowledge management literature. Using the same method, Bratianu and Orzea (2013b) have identified four components for understanding emotional knowledge.

\section{Results and discussion}

\subsection{Consistency analysis for the used instrument}

The values of reliability analysis for the entire questionnaire (except nominal and dischotomous variables) were 0,971 (Cronbach Alpha Coefficient), and 0,971 (Cronbach Alpha Coefficient - standardized items). The values of reliability analysis for the latent variable „Involvement in bioeconomy” were 0,962 (Coeficient Cronbach Alpha), and 0,960 (Coeficient Cronbach Alpha - standardized items). The analysis showed that both the entire instrument (we refer to variables Types of organizations and people; Sources of information; Involvement in bioeconomy), and the scales used for the latent variable „Involvement in bioeconomy” were reliable (show internal consistency) as Cronbach Alpha coefficients exceed 0,70 (Hair, et al., 2006). The questionnaire included scales for three latent variables, but due to limited publishing space, this article presents just one of these variables: Involvement in bioeconomy.

\section{2. „Involvement in bioeconomy" - components resulted from factor analysis}

We present below the components resulted from factor analysis (principal component analysis) of the latent variable „Involvement in bioeconomy”.

We have used Varimax rotation with Kaiser normalization. The items are presented in descending order of their loading to the appropriate component (table no. 1). It should be noted that item 14 was also loaded to component 1 (it equals to 0,515). We maintained this item in the solution due to its relevance for research. Also, total variance explained by the above solution equals to $70,62 \%$, being high enough as to enable us to maintain item 14 in the solution. The loadings over 0,516 have been displayed. As a rule, it is enough to display loadings of at least 0,50 as literature in the field reports that only loadings over 0,50 have a practical relevance (Hair, et al., 2006). For the scale used to measure involvement in bioeconomy by applying principal component analysis, we have totally eliminated 8 of 35 items in the questionnaire. The solution that was obtained by applying factor analysis is very good, the value of Kaiser-Meyer-Ohlin (KMO) tests equals to 0,868 (Pintilescu, 2007). Sig value of chi-square (Bartlett sphere test) is 0,00 ensuring that with a likelihood of $95 \%$ there is a statistically significant link among the variables (Pintilescu, 2007). Component 1 explains $45,257 \%$ of total variance, component 2: 9,688\%, component 3: $5,940 \%$, component $4: 5,296 \%$, and component 5 explains $4,440 \%$ of total variance. 
Table no. 1: Components resulted for"Involvement in bioeconomy" Rotated Component Matrix ${ }^{a}$

\begin{tabular}{|c|c|c|c|c|c|}
\hline \multirow{2}{*}{ Item } & \multicolumn{5}{|c|}{ Component } \\
\hline & 1 & 2 & 3 & 4 & 5 \\
\hline $\begin{array}{l}\text { IBE24- Having published books in Romanian language in the field of } \\
\text { bioeconomy. } \\
\text { IBE22- Having published book chapters in Romanian language in the } \\
\text { field of bioeconomy. } \\
\text { IBE32- Teaching one/several disciplines applicable to bioeconomy. } \\
\text { IBE18- Presenting papers at scientific conferences in the field of } \\
\text { bioeconomy. } \\
\text { IBE34- Supervising Bachelor's Degree papers in the field of } \\
\text { bioeconomy. } \\
\text { IBE35-Supervising internships for students in the field of bioeconomy. } \\
\text { IBE27- Purchase or use of specialized software for processing data } \\
\text { specific to bioeconomy. } \\
\text { IBE31- Collaboration with parteners (organisations in the field of } \\
\text { bioeconomy) that included direct relationships with students (for } \\
\text { example: conferences, contests, student internships). } \\
\text { IBE23- Having published book chapters in a foreign language in the } \\
\text { field of bioeconomy. } \\
\text { IBE30- Taking part in conferences for students and/or faculty at your } \\
\text { university presented by one or several organizations involved in } \\
\text { bioeconomy. } \\
\text { IBE2- Having taken courses or professional development trainings on } \\
\text { topics in the field of bioeconomy. }\end{array}$ & $\begin{array}{l}0.810 \\
0.809 \\
0.736 \\
0.710 \\
0.709 \\
0.705 \\
0.684 \\
0.683 \\
\\
0.669 \\
0.659 \\
0.571\end{array}$ & & & & \\
\hline $\begin{array}{l}\text { IBE4- Taking part in transfer of technology to businesses or research } \\
\text { institutes in the field of biotechnology. } \\
\text { IBE3- Having produced patents applicable in organizations in the field } \\
\text { of bioeconomy. } \\
\text { IBE5- Providing technical/expert consultancy to organizations } \\
\text { operating in the field of bioeconomy. } \\
\text { IBE14- Team member of research projects implemented partially or } \\
\text { totally from funds provided by one or several organizations operating } \\
\text { in the field of bioeconomy. } \\
\text { IBE13- Having been granted research grants to carry out research } \\
\text { applicable in the field of bioeconomy or biotechnology. } \\
\text { IBE15- Having received data and/or information from an organization } \\
\text { from the field of bioeconomy to carry out an ongoing research. }\end{array}$ & & $\begin{array}{l}0.820 \\
0.731 \\
0.711 \\
0.674 \\
0.559 \\
0.541\end{array}$ & & & \\
\hline $\begin{array}{l}\text { IBE11- Shareholder or single owner of a company in the field of } \\
\text { bioeconomy. } \\
\text { IBE8- Setting-up companies operating in the the field of bioeconomy. } \\
\text { IBE9- Contributing through expertise in setting up a } \\
\text { company/companies in the field of bioeconomy. } \\
\text { IBE10- Manager or employee of a company operating in the field of } \\
\text { bioeconomy. }\end{array}$ & & & $\begin{array}{l}0.840 \\
0.815 \\
0.750 \\
0.699\end{array}$ & & \\
\hline $\begin{array}{l}\text { IBE7- Participating as a speaker in professional meetings in the field of } \\
\text { bioeconomy or biotechnology. } \\
\text { IBE1-Concluding training agreements with one or several } \\
\text { organizations as a trainer on bioeconomy-related topics. } \\
\text { IBE26- Taking part in developing databases or libraries providing } \\
\text { information on bioeconomy. }\end{array}$ & & & & $\begin{array}{l}0.706 \\
0.666 \\
0.633\end{array}$ & \\
\hline $\begin{array}{l}\text { IBE19- Supervising PhD dissertations in the field of bioeconomy. } \\
\text { IBE20- Reviewing dissertations in the field of bioeconomy as a member } \\
\text { of PhD public defence committees. } \\
\text { IBE21- Reviewing research projects in the field of bioeconomy as a } \\
\text { member of committees or research projects member of committees, } \\
\text { projects }\end{array}$ & & & & & $\begin{array}{l}0.770 \\
0.727 \\
0.678\end{array}$ \\
\hline
\end{tabular}

Extraction Method: Principal Component Analysis. / Rotation Method:

Varimax with Kaiser Normalization. / a. Rotation converged in 7 iterations. Source: Own processing 
Cronbach Alpha coefficients in each item of the five components had the values that are presented below. For the items included in component 1: 0,944 (the same value also for the standardized items), component 2: 0,900 (0,904 for for the standardized items), component 3: 0,862 ( 0,865 for the standardized items), component 4: 0,722 ( 0,735 for the standardized items), and component 5: 0,813 ( 0,814 for the standardized items).

Considering the way in which the items were grouped by components, the following names were attributed to components: component 1 - Bio-Academic, component 2 - BioTech\&Science, component 3 - Bio-Entrepreneurship, component 4 - Bio-Ambassador, component 5 - Bio-Expert.

The „Bio-Academic” component includes mainly activities specific to academia, with 11 items of the scale used to measure the involvement in bioeconomy (table no. 1). This component includes knowledge flows from educational activities, in a tripartite vision that involves teachers, students and interested employers.

The „Bio-Tech\&Science” component includes technology transfer, technical or expert consultancy, and research. Therefore, this component includes both knowledge flows linked to direct relations between respondents, and companies operating in bioeconomy, as well as knowledge flows from research activities. The first category of flows of this component consists of items IBE3, IBE4 and IBE5 (table no. 1). Knowledge flows from research activities includes items from component 2: IBE13, IBE14, IBE15 (table no. 1).

The component „Bio-Entrepreneurship” includes entrepreneurial activities in the field of bioeconomy. This component includes knowledge flows linked to direct relations between respondents and companies from the field of bioeconomy. The „Bio-Ambassador" component includes items related to knowledge dissemination in bioeconomy. The „BioExpert" component consists of activities related to assessment and supervision of scientific production in this field.

\subsection{Descriptive analysis}

In what regards relative intensity of involvement in bioeconomy, the values show the lowest involvement, or are around this value. On the used scale, the lowest value of involvement for the considered types of activities is given by the value 1 (figure no. 1; table no. 2). The values are slightly over the lowest level for the „Bio-Academic” $(1,29)$, and the „Bio-Tech\&Science” $(1,31)$ components. The values are very low for the „BioEntrepreneurship” $(0,40)$, „Bio-Ambassador” $(0,79)$, and „Bio-Expert” $(0,75)$ components.

$\mathrm{H} 1$ hypothesis testing. Taking into account the values of Principal Component Analysis (PCA) that distinguished the five components, and the values of descriptive analysis, hypothesis 1 has been validated: Intensity of knowledge exchange (of respondents) differs by nature of conducted activities.

H1.1 hypothesis testing. Taking into account the values of Principal Component Analysis (PCA) that distinguished the Bio-academic component of the five components due to semantic content of the selected elements, and the results of descriptive analysis that showed that the mean intensity for this component is the second in terms of value, being slightly overcome by the Bio-Tech\&Science component, the H1.1. hypothesis has been partially 
validated: Knowledge exchange (of respondents) is more intense in academic than in other activities (activities included in Bio-Entrepreneurship, Bio-Ambassador and Bio-Expert).

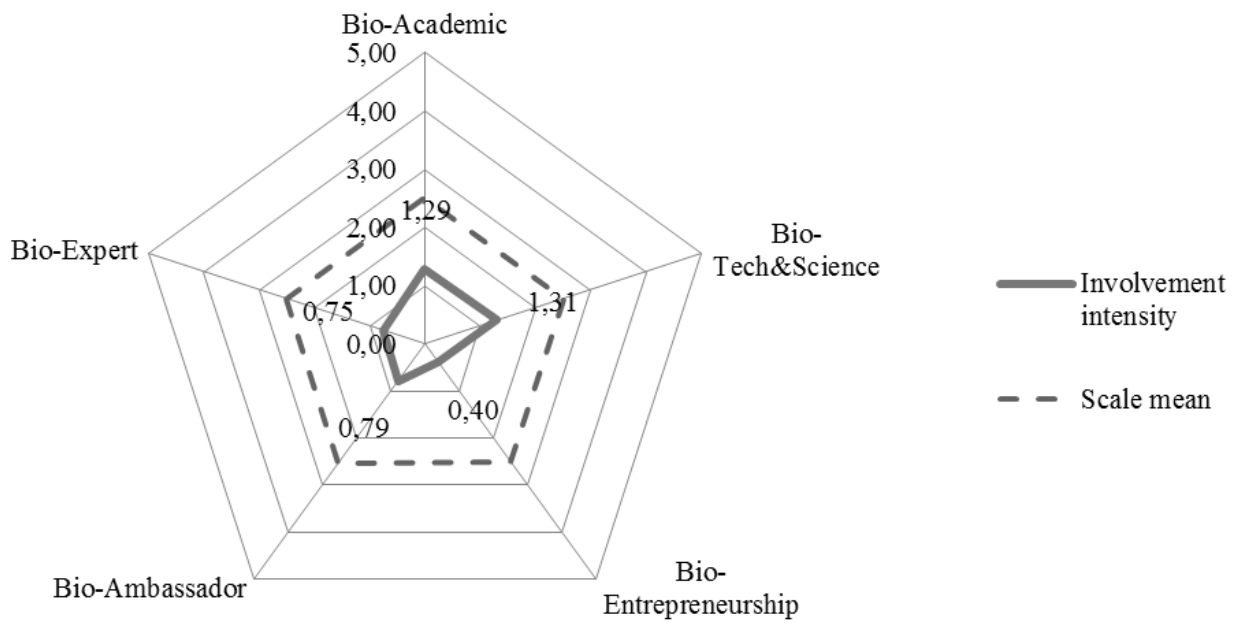

Figure no. 1: Intensity of knowledge exchange (of respondents) by components Source: Own processing

H1.2. hypothesis testing. Taking into account the values of Principal Component Analysis (PCA) that distinguished the Bio-Entrepreneurship component of the five components due to semantic content of the selected elements, and the values of descriptive analysis which showed the lowest mean intensity for this component compared to the means of the other 4 components, hypothesis H1.2. has been validated: compared with the other activities, the least intense knowledge flows (of respondents) are in entrepreneurial activities.

H2. Hypothesis testing. Taking into account that the mean of all 35 items of the questionnaire used to measure the involvement in bioeconomy was 1,0815 , and the mean of other 27 retained items in the 5 components was 1,0879, exceding the lowest involvement,

$\mathrm{H} 2$. hypothesis has been validated. This shows that in the Romanian universities there is a nucleous of intellectual capital for bioeconomy, which can represent the basis for developing a more mature bioeconomy. Only the first two components (Bio-Academic and Bio-Tech\&Science) have mean values going over the lowest involvement. The other three components (Bio-Entrepreneurship, Bio-Ambassador, Bio-Expert) have mean values under the lowest involvement (occasional, novelty for respondents). From here results that H2.1. has been partially validated, the Romanian professors and researchers being more involved in academic or technological knowledge flows.

By studying in detail thevalues of items in each component, we should make a few observations.

For the first component, „Bio-Academic”, the highest mean values were found for the items „Presenting own paper at scientific conferences in the field of bioeconomy” (mean result 1,85), „Teaching one/several disciplines applicable to bioeconomy” $(1,73)$, and „Taking part in conferences for students and/or faculty at your university presented by one 
or several organizations involved in bioeconomy." $(1,70)$. Mean values below 1 were found in the items: „Publishing books in Romanian language in the field of bioeconomy” $(0,81)$, „Publishing book chapters in Romanian language in the field of bioeconomy" $(0,77)$, „Publishing book chapters of books in a foreign language in the field of bioeconomy" $(0,71)$, and „Purchase or use of specialized software for processing data specific to bioeconomy" $(0,53)$.

Table no. 2: Descriptive analysis - Involvement in bioeconomy Descriptive Statistics

\begin{tabular}{|l|l|c|r|r|}
\hline Code & \multicolumn{1}{|c|}{ Item } & N & Mean & Std. Dev. \\
\hline IBE_F1 & Bio-Academic & 162 & 1.29 & 1.40 \\
IBE_F2 & Bio-Tech\&Science & 165 & 1.31 & 1.35 \\
IBE_F3 & Bio-Entrepreneurship & 156 & 0.40 & 0.85 \\
IBE_F4 & Bio-Ambassador & 159 & 0.79 & 1.08 \\
IBE_F5 & Bio-Expert & 159 & 0.75 & 1.22 \\
Valid N & & 154 & & \\
\hline
\end{tabular}

Source: Own processing

For the „Bio-Tech\&Science” component, the best values were recorded for having been a team member of research projects implemented partially or totally from funds provided by one or several organizations operating in the field of bioeconomy/ biotechnology (mean value 1,76 ), and for having been granted research grants to carry out research applicable in the field of bioeconomy or biotechnology $(1,69)$. The lowest mean value was recorded for having produced patents applicable in organizations in the field of bioeconomy $(0,62)$.

All items of the „Bio-Entrepreneurship” component have low values, the item „Contributing through expertise in setting up a company/ companies in the field of bioeconomy” shows a mean value closer to 1 (mean value 0,65 ), and the item „Being a shareholder or single owner of a company in the field of bioeconomy" has a mean value very close to $(0,18)$.

For the items of the „Bio-Ambassador” component, the mean values are also low, ranging between 1,08 for the item „Participating as a speaker in professional meetings in the field of bioeconomy or biotechnology”, and 0,46 for the item „Taking part in developing databases or libraries providing information on bioeconomy".

Items of the „Bio-Expert” component show very low mean values ranging from 0,88 for the item „Reviewing dissertations in the field of bioeconomy as a member of $\mathrm{PhD}$ public defence committees”, and 0,62 for the item „Supervising PhD dissertations in the field of bioeconomy".

\section{Conclusions}

The research undertaken has shown that the intensity of the involvement of teachers and researchers from Romanian universities in the knowledge flows specific to the development of the Bioeconomy varies depending on the type of activity. By means of Principal Component Analysis (PCA), 5 components have been identified that group the types of activities. They represent five areas of presence of specific knowledge flows, each with different intensity in this study. For the intellectual capital of universities, these are five areas of knowledge dynamics on which knowledge actions can be distinctly conceived. 
The level of the intensity of involvement in bioeconomy of questionnaire respondents is close to the "lowest involvement", coherent with the low maturity level of Romanian bioeconomy. The Bio-Tech\&Science (mean 1,31) and Bio-Academic (mean 1,29) are the only two components having the mean over 1 ( 1 standing for lowest involvement), showing that these two knowledge flows are the main determinants for bioeconomy development. The knowledge flows related with the „Bio-Entrepreneurship”, „Bio-Ambassador” and „Bio-Expert” are considered secondary by the professors and researchers in the sample.

For the Bio-Academic component, out of the first 7 items as a mean in descending order, the items with the mean over 1 (lowest involvement), 4 are related to relations with students, faculty and researchers, 1 to collaboration with partners for arranging student internships, 1 to investments in self-development through trainings, and 1 to paper presentations in the field of bioeconomy. Out of 4 items as a mean, 3 items under 1 (lowest involvement) are linked to publishing research (in Romanian or foreign languages), and one item is related to purchasing specific software for processing bioeconomy data.

For the Bio-Tech\&Science component, the highest means are recorded in 2 items linked to involvement of respondents in research projects, followed by 3 items related to the relation with the industry for knowledge transfer, all 5 items with a mean over 1 (lowest involvement). Only one item has a mean under „lowest involvement”, it is linked to producing patents

All items of the „Bio-Entrepreneurship” show low values, with a mean of 0,40 (closer to „I have never been involved" than to „lowest involvement"). Bio-Entrepreneurs has the lowest mean of faculty and researchers involvement, therefore the lowest intensity of knowledge flows.

Activities for dissemination of science (Bio-Ambassador) and being an expert or a member of review committees (Bio-Expert) show medium values of involvement situated around $0,70-0,80$, under the ,lowest involvement”.

These results and their interpretations must be understand in the context of the fact that 165 out of 336 validated questionnaires included the response „I have not been involved in bioeconomy" to a filter question of self-exclusion from the sample. The low level of maturity of Romanian bioeconomy hindered the response rate at the questionaire. Future research could identify the validity of these components in other geographic areas with a more mature level of bioeconomy, where the intensity of these flows can be closer to the average of supperior levels of the scale.

This study is exploratory. In the center of the statistical approach is the exploratory factor analysis. The scale that we used is reliable (it has internal consistency), which allows replication of the research in the future. However, in future research, other types of validity could be taken into consideration (for example, content validity) or a research from a confirmatory perspective (confirmatory factor analysis) can be undertaking. Among the limits of the research the measurement approach can be included. The measurement of the intensity of involvement in the knowledge flows related to bioeconomy has been carried out at the level of the respondents' perception. In future research, this type of measurement can be complemented by a measure of the concrete results indicating the level of bioeconomy development. 


\section{References}

An, Y., Han, M. and Park, Y., 2017. Identifying dynamic knowledge flow patterns of business method patents with a hidden Markov model. Scientometrics, 113(2), pp. 783-802, https://doi.org/10.1007/s11192-017-2514-8.

Bolisani, E. and Oltramari, A., 2012. Knowledge as a measurable object in business contexts: A stock and flow approach. Knowledge Management Research and Practice, 10(3), 275-286, doi:10.1057/kmrp.2012.13

Bratianu, C., 2011. Knowledge and intellectual capital. Business Excellence.

Bratianu, C. and Orzea, I., 2013a. The entropic intellectual capital model. Knowledge Management Research \& Practice, 11(2), pp. 133-141.

Bratianu, C. and Orzea, I., 2013b. Emotional knowledge: The hidden part of the knowledge iceberg. In: Proceedings of the $14^{\text {th }}$ European Conference on Knowledge Management, Kaunas University of Technology, Lithuania, 5-6 September 2013, pp. 82-90. Academic Conferences and Publishing International, Reading, UK.

Bratianu, C. and Bejinaru, R., 2017. Knowledge strategies for increasing IC of universities. In Lopez I.T. \& Serrasqueiro, R. (Eds.). Proceedings of the 9th European Conference on Intellectual Capital, Instituto Universitario de Lisboa, Lisbon, Portugal, 6-7 April 2017, pp. 34-41.

Clauss, T. and Kesting, T., 2017. How businesses should govern knowledge-intensive collaborations with universities: An empirical investigation of university professors. Industrial Marketing Management, 62, pp. 185-198. https://doi.org/10.1016/j. indmarman.2016.09.001.

Clever Consult BVBA, 2010. The Knowledge Based Bioeconomy (KBBE) in Europe: Achievements and Challenges. [pdf] Clever Consult Belgium. Available at: <http://www.mercadosbiotecnologicos.com/documents/the_knowledge_based_bioecon omy_kbbe_in_europe.pdf> [Accessed 22 February 2018].

Dabbert, S., Lewandowski, I., Weiss, J. and Pyka, A., ed. 2017. Knowledge-Driven Developments in the Bioeconomy Technological and Economic Perspectives. [e-book], Springer International Publishing AG. Available at: Springer books <http://www.springer.com/de/book/9783319583730> [Accessed 27 February 2018].

European Comission, 2005. Sixth Framework Programe, New perspectives on the knowledge-based bio-economy, Brussels, Belgium, 2005.

European Comission, 2012. Innovating for Sustainable Growth - A Bioeconomy for Europe, Brussels, Belgium, 2012.

Hair, J.F., Black, W.C., Babin, B.J., Anderson, R. E. and Tatham, R.L., 2006. Multivariate Data Analysis. Sixth Edition, New Jersey: Pearson Prentice Hall.

Henry, G. and Trigo, E., 2010. The knowledge based bio-economy at work: from large scale experiences to instruments for rural and local development, ISDA. Montpellier, France, 28-30 June 2010.

Hocevar, D.K. and Istenic, M.C., 2014. In pursuit of knowledge-based Slovenia: Is knowledge transfer to agriculture stuck in faculties?. Anthropological Notebooks, 20(3), pp. 103-120.

Luoma, P., Vanhanen, J. and Tommila, P., 2011. Distributed Bio-Based Economy - Driving Sustainable Growth. [online] Sitra, Helsinki. Available at: <https://www.sitra.fi/ julkaisut/muut/Distributed_BioBased_Economy.pdf> [Accessed 14 February 2018]. 
Näyhä, A., 2012. Towards bioeconomy: a three-phase Delphi study on forest biorefinery diffusion in Scandinavia and North America. Jyväskylä studies in business and economics. [e-journal] 117. Available through: Jyväskylä Studies in Business and Economics <https://jyx.jyu.fi/dspace/handle/123456789/40500> [Accessed 12 February 2018].

Nissen, M.E., 2006. Harnessing knowledge dynamics: Principled organizational knowing and learning. London: IRM Press.

Oliver, A. L., 2001., Strategic alliances and the learning life-cycle of biotechnology firms. Organization Studies, 22(3), pp. 467-489. https://doi.org/10.1177/0170840601223004.

Organisation for Economic Co-operation and Development, 2006. The bioeconomy to 2030: designing a policy agenda. [pdf], Paris: OECD. Available at: <http://www.oecd.org/sti/biotech/34823102.pdf> [Accessed 29 January 2018].

Organisation for Economic Co-operation and Development, 2009. The bioeconomy to 2030: designing a policy agenda. [pdf], Paris: OECD. Available at: <https://www. oecd.org/futures/long-termtechnologicalsocietalchallenges/42837897.pdf> [Accessed 29 January 2018].

Pintilescu, C., 2007. Analiză statistică multivariată, Iaşi: „Alexandru Ioan Cuza” University Publishing.

Popescu, M. and Crenicean, L., 2012. Innovation and change in education economic growth goal in Romania in the context of knowledge-based economy. Procedia - Social and Behavioral Sciences, 46, pp. 3982-3988. https://doi.org/10.1016/j.sbspro.2012.06.183.

PricewaterhouseCoopers, 2011. Regional Biotechnology. Establishing a methodology and performance indicators for assessing bioclusters and bioregions relevant to the KBBE area. [pdf] Report by $\mathrm{PwC}$ for $\mathrm{DG}$ Research and Innovation. Available at: $<$ https://www.pwc.de/de/offentliche-unternehmen/assets/neues-denken/regionalbiotech-report.pdf $>$ [Accessed 29 January 2018].

Sandu, S., 2014. Market of R\&D results in Romania, Procedia Economics and Finance, 8 , pp. 649-657. https://doi.org/10.1016/S2212-5671(14)00140-3.

Saviotti, P.P., 2017. Structural Change, Knowledge and the Bioeconomy. In Dabbert, S., Lewandowski, I., Weiss, J., Pyka, A., ed. 2017. Knowledge-Driven Developments in the Bioeconomy Technological and Economic Perspectives. [e-book], Springer International Publishing AG. Available at: Springer books <http://www.springer.com/ de/book/9783319583730> [Accessed 27 February 2018].

Sengupta, A. and Ray A., 2017. University research and knowledge transfer: A dynamic view ofambidexterity in british universities. Research Policy, 46(5), pp. 881-897, https://doi.org/10.1016/j.respol.2017.03.008.

Spatial Foresight, 2017. Bioeconomy development in EU regions. Mapping of EU Member States'/regions' Research and Innovation plans \& Strategies for Smart Specialisation (RIS3) on Bioeconomy for 2014-2020. [pdf] Available at: <https://ec.europa.eu/ research/bioeconomy/pdf/publications/bioeconomy_development_in_eu_regions.pdf > [Accessed 19 February 2018].

Tuunainen, J. and Kantasalmi, K., 2013. University and Its Societal Environments: Reflections on the Triplehelix Model. Triple Helix XI International Conference. London, England, 8-10 July 2013. Urmetzer, S., Pyka, A., 2014. Varieties of knowledge-based bioeconomies, [online] Available at: <http://nbn-resolving.de/ urn:nbn:de:bsz:100-opus-10072> [Accessed 19 February 2018]. 